\title{
Chloroplast Protein Turnover: The Influence of Extraplastidic Processes, Including Autophagy
}

\author{
Masanori Izumi 1,2,3,* (iD) and Sakuya Nakamura 2 (iD) \\ 1 Frontier Research Institute for Interdisciplinary Sciences, Tohoku University, Sendai 980-8578, Japan \\ 2 Department of Environmental Life Sciences, Graduate School of Life Sciences, Tohoku University, \\ Sendai 980-8577, Japan \\ 3 Precursory Research for Embryonic Science and Technology (PRESTO), Japan Science and Technology \\ Agency, Kawaguchi 332-0012, Japan \\ * Correspondence: m-izumi@ige.tohoku.ac.jp
}

Received: 2 February 2018; Accepted: 6 March 2018; Published: 12 March 2018

\begin{abstract}
Most assimilated nutrients in the leaves of land plants are stored in chloroplasts as photosynthetic proteins, where they mediate $\mathrm{CO}_{2}$ assimilation during growth. During senescence or under suboptimal conditions, chloroplast proteins are degraded, and the amino acids released during this process are used to produce young tissues, seeds, or respiratory energy. Protein degradation machineries contribute to the quality control of chloroplasts by removing damaged proteins caused by excess energy from sunlight. Whereas previous studies revealed that chloroplasts contain several types of intraplastidic proteases that likely derived from an endosymbiosed prokaryotic ancestor of chloroplasts, recent reports have demonstrated that multiple extraplastidic pathways also contribute to chloroplast protein turnover in response to specific cues. One such pathway is autophagy, an evolutionarily conserved process that leads to the vacuolar or lysosomal degradation of cytoplasmic components in eukaryotic cells. Here, we describe and contrast the extraplastidic pathways that degrade chloroplasts. This review shows that diverse pathways participate in chloroplast turnover during sugar starvation, senescence, and oxidative stress. Elucidating the mechanisms that regulate these pathways will help decipher the relationship among the diverse pathways mediating chloroplast protein turnover.
\end{abstract}

Keywords: autophagy; chlorophagy; chloroplasts; Rubisco-containing bodies; photooxidative damage; plants; senescence; sugar starvation; ubiquitin proteasome system; vacuole

\section{Introduction}

Chloroplasts are a type of plastid in plants and algae. In land plants, chloroplasts are present in green tissues, such as leaves, that are required for photosynthetic energy production. Within chloroplasts, thylakoid membranes contain pigments and proteins that form the light harvesting complex and electron transport chain, and the stroma contains soluble proteins that mediate the assimilation of carbon dioxide $\left(\mathrm{CO}_{2}\right)$ via the Calvin cycle. In mature plant leaves, assimilated nutrients are largely stored in chloroplasts as photosynthetic proteins. For instance, the nitrogen in chloroplasts accounts for around $75 \%$ of the total leaf nitrogen in $\mathrm{C} 3$ species [1]. The $\mathrm{CO}_{2}$-fixing enzyme ribulose-1,5-bisphosphate carboxylase/oxygenase (Rubisco) in the stroma is especially abundant, accounting for $10-30 \%$ of the total leaf nitrogen, and constituting around half of the total soluble proteins in leaves [2,3]. Chloroplast proteins are degraded, and the amino acids and other molecules released during this process are reutilized in growth. Leaf senescence is a well-established developmental process during which chloroplast proteins are degraded en masse; the released amino acids are remobilized to generate juvenile tissues and produce seeds $[4,5]$. 
A portion of the photoassimilate is accumulated in chloroplasts as starch during the day, and is degraded at night to produce sucrose as the major source for respiratory energy production within mitochondria [6]. Since the availability of solar energy fluctuates under the ever-changing environment, plants occasionally need alternatives to sugars for producing the energy required for continuous growth. Stress conditions can also interfere with photosynthetic energy production; for instance, stomatal closure due to drought stress inhibits $\mathrm{CO}_{2}$ intake and thereby reduces photosynthetic activity in leaves $[7,8]$. Plants must metabolically produce alternative energy sources to survive under photosynthesis-limited conditions. Amino acids derived from chloroplast protein degradation via catabolic pathways can serve as alternative respiratory substrates [9].

Chloroplast protein degradation is also vital for maintaining chloroplast function, as chloroplast proteins constantly accumulate damage caused by sunlight during photosynthesis. Photoinhibition occurs when the photosynthetic apparatus is damaged by excess energy from strong visible light (with wavelengths of between 400 and $700 \mathrm{~nm}$ ) [10-13]. Although chloroplasts cannot use ultraviolet-B (UVB; with wavelengths of between 280 and $315 \mathrm{~nm}$ ) for photosynthesis, various macromolecules, such as proteins, lipids, and nucleotides, directly absorb UVB, which may result in cumulative damage [14]. To maintain photosynthetic activity and avoid the overproduction of reactive oxygen species (ROS) in response to sunlight irradiation, damaged components within chloroplasts must be removed.

Turnover of chloroplastic components is required for efficient nutrient recycling during plant senescence, respiratory energy production under photoassimilate-starved conditions, and quality control in individual chloroplasts under photooxidative damage. Chloroplasts contain various types of intraplastidic proteases, which are thought to have been derived from an endosymbiosed prokaryotic ancestor of chloroplasts $[15,16]$. Recent studies of chloroplast protein turnover have further demonstrated the contribution of extraplastidic protein degradation systems to nutrient or energy recycling and the removal of damaged proteins. In this review, we describe the extraplastidic pathways that facilitate the degradation of chloroplastic components, and compare the physiological roles of these pathways and the environmental and developmental stimuli that activate them.

\section{Autophagic Degradation of Rubisco-Containing Bodies}

Autophagy is an evolutionarily conserved process in eukaryotes whereby the cell sequesters a portion of cytoplasm, including organelles, for subsequent transport into lytic organelles [17-19]. During autophagy, a nascent double membrane-bound vesicle called an autophagosome encloses a portion of the cytoplasm. The outer membrane of autophagosomes then fuses with the vacuolar or lysosomal membrane to release the inner-membrane structures, referred to as autophagic bodies, into the vacuolar or lysosomal lumen for digestion. The basic mechanism of autophagosome formation was described in the budding yeast Saccharomyces cerevisiae through the identification of autophagy (ATG) genes [20].

The ATG genes required for the initiation or elongation of autophagosomal membranes are referred as core ATGs (ATG1-10,12-14,16,18), and these genes are also required for all types of autophagy [17]. Many core ATGs function in two conjugation cascades that are required for ATG8 lipidation and autophagosomal membrane elongation. ATG7 and ATG10 conjugate ATG12 to ATG5, and the resulting ATG12-ATG5 conjugate then interacts with ATG16 to form the ATG12-ATG5-ATG16 complex. ATG8 is processed by the protease ATG4. The resulting mature ATG8 is activated by ATG7, transferred to ATG3, and is eventually conjugated with phosphatidylethanolamine with the aid of the ATG12-ATG5-ATG16 complex. Orthologues of the yeast core ATGs are conserved in plant species [21-23], and studies of autophagy-deficient atg mutants of Arabidopsis thaliana show that they have similar functions [24-32].

During leaf senescence, the amount of chloroplast stromal proteins, including Rubisco, decreases prior to the reduction in the number of chloroplasts [33-35]. Therefore, stromal proteins appear to be degraded either inside or outside the chloroplast without the breakdown of the entire chloroplast. An immuno-electron microscopy (EM) analysis of Rubisco degradation in senescing 
wheat (Triticum aestivum) leaves revealed the presence of cytosol-localized small vesicles that contained Rubisco, but not thylakoid proteins such as light-harvesting chlorophyll a/b protein of Photosystem II (LHC II), $\alpha, \beta$-subunits of coupling factor 1 in ATPase, or cytochrome $f$ [36]. These vesicles, which are around $1 \mu \mathrm{m}$ in diameter and are frequently surrounded by autophagosome-like double membranes, were originally referred to as Rubisco-containing bodies (RCBs). The development of live-cell imaging techniques using fluorescent protein markers allowed for the visualization of RCBs in vivo in Arabidopsis and rice (Oryza sativa) leaves expressing stroma-targeted green fluorescent protein (GFP) or GFP-labeled Rubisco [37,38]. This technique further demonstrated that RCBs are not produced in the mutant atg 5 or atg 7 lines, and that RCBs labeled with stroma-targeted red fluorescent proteins (RFPs) are co-localized with an autophagosomal marker, GFP-ATG8. These observations revealed that RCBs are a type of autophagic body that delivers a portion of the stromal proteins into the vacuole. Thus, the RCB pathway was established as an autophagic process that mobilizes stromal proteins to the vacuole (Figure 1a).

Endosomal sorting complex required for transport (ESCRT) proteins are part of an evolutionarily conserved system that is responsible for the remodeling of endosomal membranes in eukaryotes [39]. A recent study in Arabidopsis indicated that the ESCRT-III paralogs charged multivesicular body protein 1A (CHMP1A) and CHMP1B are required for the delivery of RCBs to the vacuole [40]. In chmp1a chmp1b double mutant plants, RCBs were produced but accumulated in the cytoplasm; therefore, CHMP1 proteins are required for the vacuolar sorting of chloroplast-derived RCBs or the fusion of autophagosomes enclosing RCBs. How a portion of stroma is separated as RCBs, and how RCBs are then recruited for autophagic transport remain unclear.

The RCB pathway is particularly active in sugar-starved, excised Arabidopsis leaves in darkness or the presence of photosynthesis inhibitors [41]. Starch is the major carbohydrate form for energy storage. The starchless mutants, phosphoglucomutase (pgm) and ADP-glucose pyrophosphorylase1 (adg1), which lack starch, exhibited enhanced production of RCBs [41,42]. Moreover, starchless and atg double mutants exhibited reduced growth and enhanced cell death during developmental senescence compared to the respective single mutants [42]. These results indicate that the RCB pathway plays a role in the response to sugar starvation. Recent studies found that in the sugar-starved leaves of Arabidopsis plants maintained in complete darkness for several days, autophagy deficiency compromises the release of free amino acids, especially free branched chain amino acids (BCAAs) like isoleucine, leucine, and valine $[43,44]$. Arabidopsis mutants with defects in the enzymes involved in BCAA catabolism have reduced tolerance to sugar starvation due to prolonged complete darkness [9,45-49]; thus, BCAAs are a particularly important energy source for mitochondrial respiration as alternatives to sugars. The RCB pathway might supply free amino acids, especially BCAAs, derived from vacuolar degradation of stromal proteins as an alternative energy source during periods of impaired photosynthesis (Figure 1a).

Photosynthetic energy production can be perturbed by various types of suboptimal conditions, including shading, flooding, or drought. The importance of core autophagy machinery during submergence-induced hypoxia or draught stress was reported in Arabidopsis plants [50,51]. The RCB pathway might alleviate the energy limitation that is caused by some types of abiotic stresses.

RCB production is also activated during accelerated leaf senescence induced in leaves that were individually covered to impair photosynthesis [52]. This activation of senescence corresponds to chloroplast shrinkage. In addition to direct observations of RCBs labeled with stroma-localized fluorescent proteins, the activity of the RCB pathway can be monitored by biochemical detection of free GFP or RFP derived from vacuolar degradation of Rubisco-GFP or -RFP fusion proteins, which are mobilized to the vacuole via RCBs [53]. This technique indicated that autophagy contributes substantially to the degradation of Rubisco in individually darkened leaves and in those shaded by the leaves of neighboring Arabidopsis plants [53]. Such biochemical methods of monitoring the RCB pathway have also been established in rice plants, and have shown that Rubisco is degraded via RCBs in individually darkened rice leaves [38]. In autophagy-deficient atg mutant rice plants, osatg7, Rubisco degradation was attenuated in senescing leaves, which is consistent with the partly compromised 
nitrogen remobilization from lower leaves to newly developing upper leaves [54]. These findings further indicate that the RCB pathway mediates nitrogen remobilization from older leaves that cannot acquire sufficient light due to shading of developing leaves by upper tissues.

Analyses of Arabidopsis and maize (Zea mays) plants harboring the atg mutation indicated that autophagy contributes to nitrogen remobilization from vegetative tissues to reproductive tissues, including seeds [55-57]. However, such a role for autophagy in rice plants was not evaluated, because autophagy-deficient rice plants exhibit male sterility due to impaired pollen maturation [58].

\section{Chlorophagy: Degradation of Entire Chloroplasts}

Whereas the amount of stromal proteins decreases during the earlier stages of leaf senescence in wheat or barley (Hordeum vulgare) plants, the number of chloroplasts per cell decreases during the later stages [33-35]. In individually darkened leaves of wild-type Arabidopsis plants, RCB production and subsequent shrinkage of chloroplasts occur during the earlier stages of senescence, and the chloroplast population decreases during the later stages of senescence [52]. This decrease in chloroplast number is suppressed in atg 4 mutants. Some isolated vacuoles from the darkened leaves of wild-type plants contained chloroplasts that exhibited chlorophyll autofluorescence signals. These findings suggest that shrunken chloroplasts, which are produced through the active separation of their components in the RCB pathway, become the targets of autophagic transport as entire organelles, a process known as chlorophagy [59] (Figure 1b).

In yeast and mammals, autophagy is also recognized as a major quality control system for organelles through the selective removal of dysfunctional organelles [19]. In Arabidopsis atg plants, oxidized peroxisomes containing aggregated catalase accumulate in the cytoplasm of senescing leaves [60-62]. During germination, enzymes in peroxisomes catalyze $\beta$-oxidation and the glyoxylate cycle, thereby allowing lipids stored in seeds to be used as energy before photosynthetic machinery within chloroplasts are developed. As photosynthetic growth is established several days after germination, peroxisomes are remodeled to carry out the glycolate pathway, which is required for photorespiration. This functional conversion of peroxisomes was partly compromised in Arabidopsis atg plants in which peroxisome aggregates accumulate in mesophyll cells containing mature chloroplasts $[63,64]$. Thus, plant peroxisomes are likely targets of a process of selective autophagy known as pexophagy during senescence or seedling development. Autophagic degradation of the endoplasmic reticulum (ER) during ER stress due to tunicamycin treatment was also observed in Arabidopsis roots $[65,66]$. Selective degradation of ER by autophagy termed ER-phagy may function in plants.

A recent study investigated the involvement of autophagy in the turnover of chloroplasts under photooxidative stress conditions and demonstrated that chlorophagy is induced in Arabidopsis leaves damaged by UVB exposure [67]. A subset of the chloroplasts in the cytoplasm of UVB-damaged atg5 and atg7 plants exhibited irregular shapes and disorganized thylakoid structures. Chlorophagy was also induced by chloroplast damage caused by exposure to strong visible light or natural sunlight. Therefore, chlorophagy may remove entire photo-damaged chloroplasts by transporting them into the vacuole $[67,68]$ (Figure 1c).

The chloroplast-targeted RCB pathway and chlorophagy differ in individually darkened leaves and in leaves subjected to UVB damage $[67,69]$. During sugar starvation in individually darkened leaves, RCBs were observed after $1 \mathrm{~d}$ of treatment, whereas chlorophagy was rarely observed during 3 days of dark treatment. By contrast, in leaves subjected to UVB-mediated oxidative stress, chlorophagy was actively induced 2 days after treatment without prior RCB production. These observations suggest that the induction of these two types of autophagy is individually controlled by distinct upstream mechanisms in response to environmental or developmental conditions (Figure 1). 


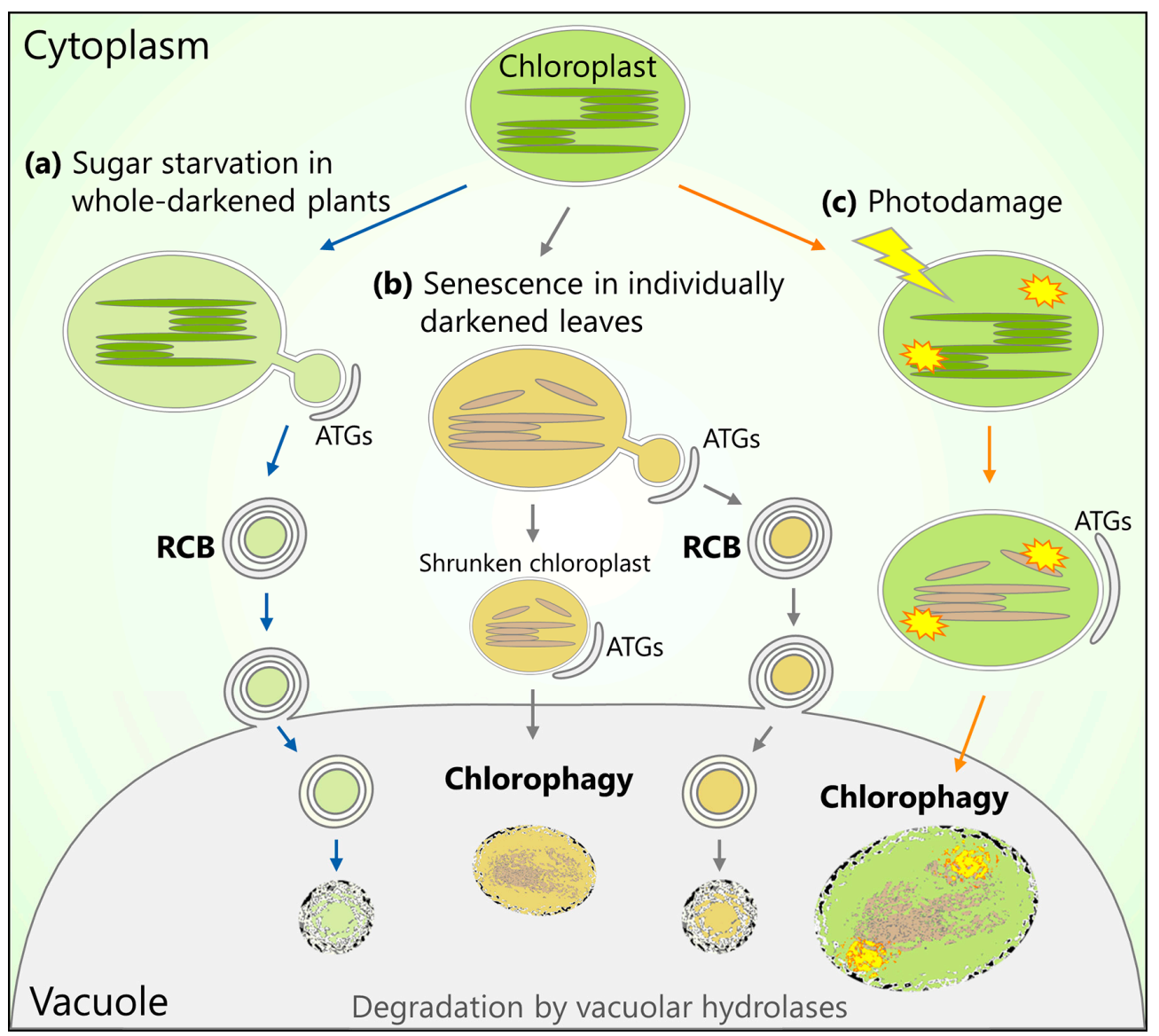

Figure 1. Schematic model for the Rubisco-containing body (RCB) pathway and chlorophagy forms of chloroplast-related autophagy. (a) When photosynthetic energy production of whole plants is impaired due to complete darkness, a portion of the chloroplast stroma is transported to the central vacuole via RCBs, which are a type of autophagic compartment that specifically contains stromal proteins. The RCB pathway can facilitate the recycling of amino acids as an energy source. (b) When senescence is accelerated in individually darkened leaves, the active production of RCBs leads to chloroplast shrinkage, thereby allowing the transport of entire chloroplasts to the vacuole via chlorophagy. (c) Photodamage from exposure to ultraviolet-B (UV-B), strong visible light, or natural sunlight causes chloroplasts to collapse. The collapsed chloroplasts are then transported to the vacuole without prior activation of RCBs. This process is suggested to serve as a quality control mechanism that removes damaged chloroplasts.

\section{ATI Body-Mediated Chloroplast Degradation}

ATG8 is a core ATG protein that builds up the autophagosomal membrane by conjugating with phosphatidylethanolamine [70]. In yeast, several types of organelle-targeted autophagy are controlled by ATG proteins containing an ATG8-interacting motif (AIM) [71]. ATG32 triggers the removal of dysfunctional or excess mitochondria by interacting with autophagosomal membrane-anchored ATG8 on the mitochondrial outer envelope [72,73]. ATG39 and ATG40 were also identified as ATG8-interacting proteins that control nucleus- or ER-targeted selective autophagy, respectively [74].

ATG8-interacting protein 1 (ATI1) and ATI2 were identified in a yeast two-hybrid screen for candidates that interact with the Arabidopsis ATG8 isoform, ATG8f [75]. These proteins were found to associate with plastids in addition to the ER as small vesicles of approximately $1 \mu \mathrm{m}$ in diameter, which are referred to as ATI bodies [76]. A screen of potential ATI1-interacting proteins and microscopy observations of fluorescent marker proteins indicated that plastid-associated ATI bodies transport some thylakoid, stroma, and envelope proteins into the vacuole, especially under dark-induced 
energy limitation [76]. These delivery cargos differ from those of the RCBs that specifically contain a portion of stroma [36,37]; however, the vacuolar transport of plastid-associated ATI bodies is an autophagy-dependent process, as this body was not produced in the atg5 mutants [76]. Therefore, ATI bodies represent a distinct form of autophagy vesicles that transport some stroma, thylakoid, and envelope components into the vacuole (Figure 2a). Plastid-associated ATI bodies are also observed inside the chloroplast, and ATI1 interacts with some thylakoid proteins in vivo [76]. It is thus proposed that plastid-associated ATI bodies form in chloroplasts and are then delivered into the vacuole via autophagosome-mediated transport (Figure 2a), although how such bodies are evacuated from chloroplasts remains unclear.

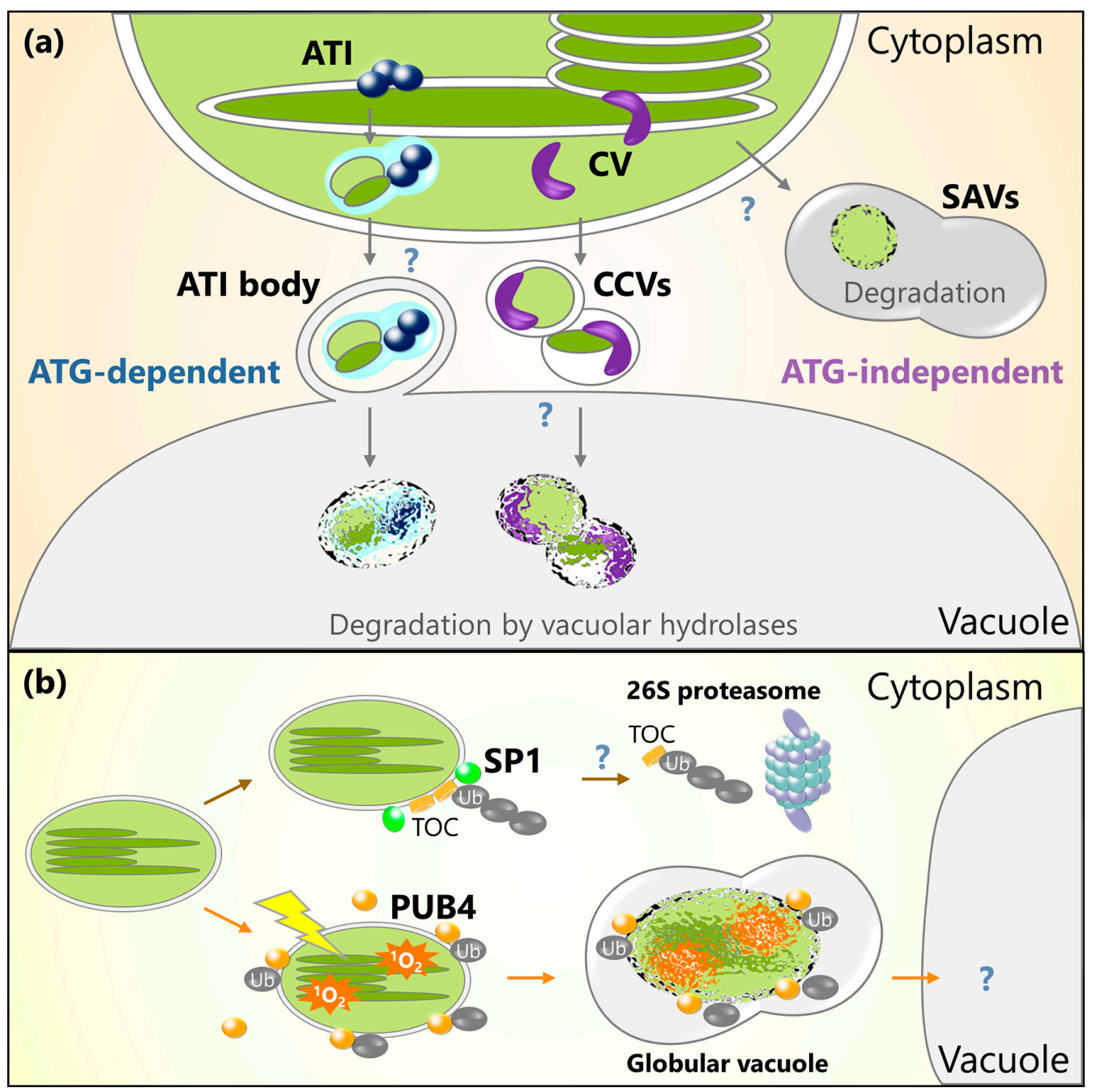

Figure 2. Schematic model for chloroplast protein turnover mediated by ATI bodies, CV-containing vesicles (CCVs), senescence-associated vacuoles (SAVs), or ubiquitination. (a) Plastid-associated ATI bodies are produced in chloroplasts and are then delivered into the central vacuole via an autophagy-dependent pathway. ATI bodies transport thylakoid, stroma, and envelope proteins. $\mathrm{CV}$ protein also interacts with thylakoid and stroma proteins, and then induces the production of CCVs that transport thylakoid, stroma, and envelope proteins into the central vacuole via an autophagy-independent pathway. SAVs are small lytic compartments that form in the cytoplasm. Stroma components are incorporated into the SAVs for digestion. (b) Chloroplast outer envelope-anchored E3 ligase, SP1, ubiquitinates TOC proteins and facilitates their degradation by $26 \mathrm{~S}$ proteasome. Cytoplasmic E3 ligase PUB4 ubiquitinates oxidative chloroplasts accumulating ${ }^{1} \mathrm{O}_{2}$ for the digestion of such chloroplasts in their entirety. 
The appearance of plastid-associated ATI bodies in energy-starved seedlings or senescing leaves suggests that ATI bodies also contribute to amino acid recycling during starvation or senescence as part of the autophagy process, although the link between the induction level of the ATI bodies and changes in free amino acid content has not been evaluated. Additionally, plastid-associated ATI bodies are produced under salt stress, and ATI-knockdown plants have reduced salt tolerance [76]. The activation of autophagosome production and the reduced tolerance of atg mutants to salt stress were also observed in Arabidopsis plants [50,77]. These findings suggest that ATI bodies are involved in salt stress-induced chloroplast protein turnover.

\section{Senescence-Associated Vacuoles}

The formation of small, lytic senescence-associated vacuoles (SAVs) was reported when senescing leaves of Arabidopsis, soybean (Glycine max), and tobacco (Nicotiana tabacum) plants were stained with R-6502 dye, which emits strong fluorescence upon the hydrolytic activity of cysteine proteases [78,79]. Senescence-associated gene 12 (SAG12) is a senescence-induced cysteine protease localized within SAVs. SAVs are formed in the peripheral cytoplasmic region of mesophyll cells and are much smaller than the central vacuole, being approximately $0.7 \mu \mathrm{m}$ in diameter. In addition, SAVs have greater lytic activity than the central vacuole and are strongly stained by lysotracker red or neutral red, fluorescent markers of acidic organelles.

SAV numbers increase as leaf senescence progresses [80]. Proteomic analysis of isolated SAVs in tobacco plants indicated that SAVs contain stromal proteins such as Rubisco and glutamine synthetase, but not thylakoid proteins such as LHCII and the reaction center D1 protein in photosystem II [79]. Treatment with a specific inhibitor of cysteine proteases, E-64, partially suppressed Rubisco degradation in the tobacco leaf discs [80]. These observations suggest that SAVs contribute to senescence-induced Rubisco degradation, similar to RCBs; however, atg7 mutants produced SAVs [79]. Therefore, SAVs may be an autophagy-independent, extra-chloroplastic route for the degradation of stromal proteins in senescent leaves (Figure 2a). How stromal proteins are transported into the SAVs remains uncertain.

\section{Autophagy-Independent Vesicles Derived from Chloroplasts}

The chloroplast vesiculation $(\mathrm{CV})$ gene encodes a plastid-targeted protein in rice plants that is strongly upregulated under abiotic stress and downregulated by cytokinin [81]. In Arabidopsis, expression of the CV-GFP construct under the control of the dexamethasone-inducible promoter caused the formation of a type of chloroplast-derived vesicle exhibiting strong CV-GFP signal referred to as $\mathrm{CV}$-containing vesicles (CCVs) [81]. CCVs are around $1 \mu \mathrm{m}$ in diameter and contain stroma, envelope, and thylakoid proteins, as demonstrated by immunoblot analysis of some chloroplast proteins, co-immunoprecipitation assays of potential CV-interacting protein, and confocal microscopy of fluorescent marker proteins of chloroplast stroma [81]. CCVs do not associate with the autophagosome marker GFP-ATG8a, and the atg5 mutation does not affect the production of CCVs. Additionally, CCVs do not associate with SAVs stained with lysotracker red. Thus, CCVs are part of a vacuolar degradation process for chloroplasts that is independent of autophagy and SAVs (Figure 2a).

Immuno-EM analysis showed that CV-GFP was associated with the thylakoid or envelope membranes before CCV production [81]. The interaction of CV with PsbO protein, a subunit in the thylakoid-bound photosystem II complex, was confirmed by co-immunoprecipitation detection and a bimolecular fluorescence complementation (BiFC) assay. These results indicate that $\mathrm{CV}$ interacts with some proteins inside the chloroplast before CCVs form. The C-terminal domain of CV, which is largely conserved among CV orthologs of various plant species, is required for CCV production [81]; however, how chloroplast-targeted CV induces the formation of CCVs and chloroplast destabilization has not been evaluated.

In Arabidopsis plants, endogenous $C V$ was upregulated in senescing leaves and leaves subjected to oxidative stress or salt stress [81]. Consistent with this, transient expression of $C V$ caused accelerated leaf senescence, and the suppression of $C V$ transcript by miRNA led to increased leaf longevity under 
salt stress. Similarly, in rice plants, the RNAi silencing of $C V$ expression led to delayed leaf senescence under water deficit stress, and the transient overexpression of $C V$-GFP under the control of the $\beta$-estradiol-inducible promoter accelerated leaf senescence symptoms [82]. Elevated $C V$ transcript levels were observed in UVB-damaged Arabidopsis leaves [67]. CV may activate the destabilization and degradation of chloroplasts through the formation of CCVs during senescence, especially under stress conditions in Arabidopsis and rice plants.

\section{Ubiquitin E3 Ligase-Associated Chloroplast Degradation}

The ubiquitin proteasome system (UPS) is an evolutionarily conserved major protein degradation system in eukaryotic cells [83-85]. During UPS-mediated proteolysis, the polypeptide ubiquitin acts as a sorting signal for the degradation of specific proteins by the $26 \mathrm{~S}$ proteasome in the ubiquitination cascade. Ubiquitin is activated by E1 proteins and then transferred to E2 ubiquitin conjugating enzymes. The transfer of ubiquitin from E2s to target proteins requires E3 ubiquitin ligases. The resulting ubiquitinated proteins are selectively incorporated into the $26 \mathrm{~S}$ proteasome complex for breakdown. Eukaryotic genomes generally encode a large family of E3s and Arabidopsis plants can theoretically express more than 1500 of these proteins [86-88]. The ubiquitination of specific proteins by individual E3s allows for highly controlled, selective protein degradation by the UPS.

The UPS was shown to contribute to the degradation of chloroplast proteins in an experiment using suppressor of ppi1 locus 1 (SP1) isolated from Arabidopsis plants [89]. SP1 is a chloroplast outer envelope-anchored E3 ligase that ubiquitinates some proteins of the translocon on the outer chloroplast membrane (TOC) complex (Figure 2b). Most nucleus-encoded chloroplast proteins are imported into chloroplasts through the TOC and translocon on the inner chloroplast membrane (TIC) complexes [90]. During the greening of etiolated seedlings, etioplasts, which are a type of plastid present in non-green tissues, are converted to mature chloroplasts; therefore, large amount of photosynthetic proteins encoded in the nuclear genome are expressed and imported into the plastid via TIC-TOC complexes. $s p 1$ mutant plants exhibit delayed maturation of chloroplasts during the greening of etiolated seedlings [89]. Thus, SP1 likely serves as a control for protein import into chloroplasts via the turnover of the TOC complex when etioplasts develop into functional chloroplasts. sp1 mutants also showed delayed leaf yellowing during dark-induced accelerated senescence; conversely, SP1-overexpressing plants showed an enhanced decline of photosynthetic efficiency [89]. SP1-mediated TOC turnover may further regulate protein import into chloroplasts when functional chloroplasts are actively degraded during senescence.

SP1 induces the degradation of TOC during oxidative stress caused by salt or osmotic stress, thereby attenuating protein import into the chloroplasts [91]. Under these stress conditions, accumulation of hydrogen peroxide $\left(\mathrm{H}_{2} \mathrm{O}_{2}\right)$, a type of ROS, was enhanced in $s p 1$ mutants and was alleviated in SP1-overexpressing plants. SP1-mediated degradation of the TOC complex by UPS suppresses photosynthetic activity and thereby limits ROS production [91], since ROS are produced during photosynthesis. SP1-mediated TOC turnover may therefore control the chloroplast proteome and photosynthetic capacity in response to stress. It is still unclear how ubiquitinated proteins on outer-envelope proteins are solubilized to allow degradation by UPS localized in the cytoplasm.

A recent study reported that a cytosol-localized E3 ligase functions in the degradation of entire chloroplasts [92]. When dark-germinated, etiolated seedlings of the Arabidopsis mutant of plastid ferrochelatase $2(f c 2)$ are transferred from darkness to light, their chloroplasts over-accumulate singlet oxygen $\left({ }^{1} \mathrm{O}_{2}\right)$, thereby leading to the death of photosynthetic cells and compromised greening of plants. A suppressor mutant (referred to as pub4-6 [92]) of this inhibited greening phenomenon had an amino acid substitution in plant $u$-box 4 (PUB4), which encodes a cytosolic ubiquitin E3 ligase. Although $\mathrm{EM}$ analysis indicated that entire chloroplasts were digested in the cytoplasm during compromised greening in $f c 2$ plants, this degradation of chloroplasts was lower in $f c 2$ pub4-6 plants, even though ${ }^{1} \mathrm{O}_{2}$ accumulation was not suppressed. Therefore, PUB4-related ubiquitination triggers the digestion of entire chloroplasts that are accumulating ${ }^{1} \mathrm{O}_{2}$ (Figure $2 \mathrm{~b}$ ). However, unlike the pub4-6 mutation, 
the T-DNA insertional knockout mutations of PUB4 (referred to as pub4-1 and pub4-2) did not suppress the phenotype of the $f c 2$ mutant during greening [92]. Therefore, it is unclear how PUB4 is involved in the ubiquitination of ${ }^{1} \mathrm{O}_{2}$ accumulating chloroplasts and their subsequent degradation.

In mammalian cells, ubiquitination largely acts as a trigger of autophagic removal of dysfunctional organelles [93]. During mitophagy, depolarized mitochondria are ubiquitinated by the E3 ligase Parkin, allowing for the autophagic removal of targeted mitochondria into the lysosome [94-97]. During the greening of $f c 2$ mutants, some chloroplasts appeared to be degraded in the cytoplasm, and the interaction between degrading chloroplasts and the vacuole via a globule-like structure was observed [92]. Such observations were distinct from the vacuolar chloroplasts that result from chlorophagy in leaves exposed to strong visible light $\left(1200-2000 \mu \mathrm{mol} \cdot \mathrm{m}^{-2} \cdot \mathrm{s}^{-1}\right)$, where entire chloroplasts exhibiting thylakoid membranes are localized in the central vacuole in EM imaging [67]. Furthermore, the pub4-6 and atg10 mutants are phenotypically distinct, as atg10 plants showed accelerated senescence during dark treatment compared to wild-type plants, but pub4-6 plants did not [92]. Therefore, PUB4-related ubiquitination is unlikely a simple trigger of autophagy.

\section{Future Perspectives}

Our understanding of the diverse extraplastidic pathways mediating chloroplast protein degradation has progressed in the past decades. Table 1 compares their relationships to core autophagy machinery, plant species, induction stimuli, and degradation targets. It is clear that multiple pathways are induced during diverse stress conditions, such as sugar starvation, senescence, and oxidative stress (Table 1). Thus, new questions about chloroplast turnover arise, including why plants have multiple processes for chloroplast protein turnover, and how these processes are differentially utilized. Future research should examine how extraplastidic systems are coordinated with intraplastidic proteolysis. The RCB pathway is activated during the earlier stages of dark treatment and chlorophagy is induced during the later stages [52,67], suggesting that several pathways are induced at distinct time points during leaf senescence and stress responses. An important role of intrachloroplastic proteases in chloroplast protein turnover during photodamage was largely demonstrated $[15,16]$. Therefore, extraplastidic pathways that are induced during photooxidative stress might be triggered when intraplastidic proteolysis is insufficient for maintaining chloroplast functions.

Table 1. List of extraplastidic degradation pathways described.

\begin{tabular}{|c|c|c|c|c|c|}
\hline Pathway & $\begin{array}{l}\text { Relationship to Core } \\
\text { Autophagy Machinery }\end{array}$ & $\begin{array}{l}\text { Analyzed } \\
\text { Species }\end{array}$ & $\begin{array}{l}\text { Degradation } \\
\text { Targets }\end{array}$ & Stimuli $^{b}$ & References \\
\hline $\begin{array}{c}\text { RCBs } \\
\text { (Rubisco-containing } \\
\text { bodies) }\end{array}$ & dependent & $\begin{array}{l}\text { Arabidopsis, } \\
\text { rice, wheat }\end{array}$ & $\begin{array}{c}\text { stroma, } \\
\text { envelope }\end{array}$ & $\begin{array}{l}\text { sugar starvation, } \\
\text { senescence }\end{array}$ & {$[36-38,41,42,44,52-54]$} \\
\hline Chlorophagy & dependent & Arabidopsis & $\begin{array}{c}\text { entire } \\
\text { chloroplasts }\end{array}$ & $\begin{array}{l}\text { photodamage, } \\
\text { senescence }\end{array}$ & {$[52,67]$} \\
\hline $\begin{array}{c}\text { SAVs } \\
\text { (Senescence-associated } \\
\text { vacuoles) }\end{array}$ & independent & $\begin{array}{c}\text { Arabidopsis, } \\
\text { soybean, } \\
\text { tobacco }\end{array}$ & stroma & senescence & [78-80] \\
\hline $\begin{array}{c}\text { CCVs (Chloroplast } \\
\text { vesiculation-containing } \\
\text { vesicles) }\end{array}$ & independent & $\begin{array}{l}\text { Arabidopsis, } \\
\text { rice }\end{array}$ & $\begin{array}{l}\text { stroma, } \\
\text { thylakoid, } \\
\text { envelope }\end{array}$ & $\begin{array}{l}\text { senescence, salt } \\
\text { stress, oxidative } \\
\text { stress }\end{array}$ & {$[81,82]$} \\
\hline E3 ligase PUB4 & $-a$ & Arabidopsis & $\begin{array}{c}\text { entire } \\
\text { chloroplasts }\end{array}$ & $\begin{array}{l}\text { Oxidative stress } \\
\left({ }^{1} \mathrm{O}_{2}\right)\end{array}$ & [92] \\
\hline
\end{tabular}

${ }^{a}$ The link of the E3 ubiquitin ligases to autophagy has not been directly examined. ${ }^{b}$ Stimuli inducing the respective pathways. 
In Arabidopsis atg plants, both $C V$ expression and proteasome activity are increased $[43,98]$, suggesting a complementary relationship among some of the chloroplast-associated degradation systems. However, since senescence symptoms are largely accelerated in atg mutants due to the over-accumulation of salicylic acid [99], the increase in $C V$ expression or proteasome activity in atg plants can also be interpreted as a result of accelerated senescence and cell death. To better understand the process of chloroplast protein turnover and to decipher the relationships among the diverse pathways mediating this process, the mechanisms regulating these pathways will need to be elucidated. It would be fascinating to determine whether the distinct pathways that mediate chloroplast degradation share a common upstream regulatory mechanism, or whether they are regulated independently. In addition, how small vesicles delivering portions of chloroplasts, including RCBs, ATI bodies, and CCVs, are derived from entire chloroplasts largely remains to be explained.

The extraplastidic routes for chloroplast protein turnover were largely identified using Arabidopsis plants (Table 1). This advance greatly expanded our understanding of chloroplast protein turnover in important cereals, such as rice and maize $[38,54,56,82]$. Chloroplast degradation is strongly linked to nitrogen remobilization and the changes of photosynthetic capacity that are important determinants of productivity in crop plants. Therefore, manipulating chloroplast protein turnover might be an effective strategy to improve the productivity of crops. In rice plants, RNAi-mediated silencing of $C V$ led to an increase in grain yield under water deficit stress [74]. Studies showed that Arabidopsis plants overexpressing one of the core ATGs had an enhanced stress tolerance $[100,101]$. In addition, SP1-overexpressing Arabidopsis plants had improved tolerance to oxidative stress [91]. Therefore, elucidating the molecular basis of multiple processes for chloroplast protein turnover in Arabidopsis plants may suggest strategies to improve the productivity and stress tolerance of crop plants.

Acknowledgments: This work was supported, in part, by KAKENHI (Grant Numbers 17H05050, awarded to Masanori Izumi and 16J03408, awarded to Sakuya Nakamura), the JSPS Research Fellowship for Young Scientists (awarded to Sakuya Nakamura), Building of Consortia for the Development of Human Resources in Science and Technology (awarded to Masanori Izumi), JST PRESTO (Grant Number JPMJPR16Q1, awarded to Masanori Izumi), and the Program for Creation of Interdisciplinary Research at Frontier Research Institute for Interdisciplinary Sciences, Tohoku University, Japan (awarded to Masanori Izumi).

Author Contributions: Masanori Izumi conceived the topic of this review; Masanori Izumi and Sakuya Nakamura wrote the paper; Sakuya Nakamura designed the figures with the support of Masanori Izumi.

Conflicts of Interest: The authors declare no conflicts of interest.

\section{References}

1. Makino, A.; Osmond, B. Effects of nitrogen nutrition on nitrogen partitioning between chloroplasts and mitochondria in pea and wheat. Plant Physiol. 1991, 96, 355-362. [CrossRef] [PubMed]

2. Makino, A.; Sakuma, H.; Sudo, E.; Mae, T. Differences between maize and rice in N-use efficiency for photosynthesis and protein allocation. Plant Cell Physiol. 2003, 44, 952-956. [CrossRef] [PubMed]

3. Evans, J.R. Photosynthesis and nitrogen relationships in leaves of $C_{3}$ plants. Oecologia 1989, 78, 9-19. [CrossRef] [PubMed]

4. Mae, T.; Ohira, K. The remobilization of nitrogen related to leaf growth and senescence in rice plants (Oryza sativa L.). Plant Cell Physiol. 1981, 22, 1067-1074. [CrossRef]

5. Masclaux-Daubresse, C.; Daniel-Vedele, F.; Dechorgnat, J.; Chardon, F.; Gaufichon, L.; Suzuki, A. Nitrogen uptake, assimilation and remobilization in plants: Challenges for sustainable and productive agriculture. Ann. Bot. 2010, 105, 1141-1157. [CrossRef] [PubMed]

6. Stitt, M.; Zeeman, S.C. Starch turnover: Pathways, regulation and role in growth. Curr. Opin. Plant Biol. 2012, 15, 282-292. [CrossRef] [PubMed]

7. Baena-González, E.; Sheen, J. Convergent energy and stress signaling. Trends Plant Sci. 2008, 13, 474-482. [CrossRef] [PubMed]

8. Chaves, M.M.; Flexas, J.; Pinheiro, C. Photosynthesis under drought and salt stress: Regulation mechanisms from whole plant to cell. Ann. Bot. 2009, 103, 551-560. [CrossRef] [PubMed] 
9. Araújo, W.L.; Tohge, T.; Ishizaki, K.; Leaver, C.J.; Fernie, A.R. Protein degradation-An alternative respiratory substrate for stressed plants. Trends Plant Sci. 2011, 16, 489-498. [CrossRef] [PubMed]

10. Sonoike, K. Various aspects of inhibition of photosynthesis under light/chilling stress: "Photoinhibition at chilling temperatures" versus "Chilling damage in the light". J. Plant Res. 1998, 111, 121-129. [CrossRef]

11. Li, Z.R.; Wakao, S.; Fischer, B.B.; Niyogi, K.K. Sensing and responding to excess light. Annu. Rev. Plant Biol. 2009, 60, 239-260. [CrossRef] [PubMed]

12. Tikkanen, M.; Mekala, N.R.; Aro, E.M. Photosystem II photoinhibition-repair cycle protects Photosystem I from irreversible damage. Biochim. Biophys. Acta 2014, 1837, 210-215. [CrossRef] [PubMed]

13. Takahashi, S.; Badger, M.R. Photoprotection in plants: A new light on photosystem II damage. Trends Plant Sci. 2011, 16, 53-60. [CrossRef] [PubMed]

14. Kataria, S.; Jajoo, A.; Guruprasad, K.N. Impact of increasing Ultraviolet-B (UV-B) radiation on photosynthetic processes. J. Photochem. Photobiol B 2014, 137, 55-66. [CrossRef] [PubMed]

15. Nishimura, K.; Kato, Y.; Sakamoto, W. Chloroplast proteases: Updates on proteolysis within and across suborganellar compartments. Plant Physiol. 2016, 171, 2280-2293. [CrossRef] [PubMed]

16. Van Wijk, K.J. Protein maturation and proteolysis in plant plastids, mitochondria, and peroxisomes. Annu Rev. Plant Biol. 2015, 66, 75-111. [CrossRef] [PubMed]

17. Nakatogawa, H.; Suzuki, K.; Kamada, Y.; Ohsumi, Y. Dynamics and diversity in autophagy mechanisms: Lessons from yeast. Nat. Rev. Mol. Cell Biol. 2009, 10, 458-467. [CrossRef] [PubMed]

18. Mizushima, N.; Komatsu, M. Autophagy: Renovation of cells and tissues. Cell 2011, 147, 728-741. [CrossRef] [PubMed]

19. Anding, A.L.; Baehrecke, E.H. Cleaning house: Selective autophagy of organelles. Dev. Cell 2017, 41, 10-22. [CrossRef] [PubMed]

20. Tsukada, M.; Ohsumi, Y. Isolation and characterization of autophagy-defective mutants of Saccharomyces erevisiae. FEBS Lett. 1993, 333, 169-174. [CrossRef]

21. Chung, T.; Suttangkakul, A.; Vierstra, R.D. The ATG autophagic conjugation system in maize: ATG transcripts and abundance of the ATG8-lipid adduct are regulated by development and nutrient availability. Plant Physiol. 2009, 149, 220-234. [CrossRef] [PubMed]

22. Xia, K.F.; Liu, T.; Ouyang, J.; Wang, R.; Fan, T.; Zhang, M.Y. Genome-wide identification, classification, and expression analysis of autophagy-associated gene homologues in rice (Oryza sativa L.). DNA Res. 2011, 18, 363-377. [CrossRef] [PubMed]

23. Meijer, W.H.; van der Klei, I.J.; Veenhuis, M.; Kiel, J.A.K.W. ATG genes involved in non-selective autophagy are conserved from yeast to man, but the selective Cvt and pexophagy pathways also require organism-specific genes. Autophagy 2007, 3, 106-116. [CrossRef] [PubMed]

24. Yoshimoto, K.; Hanaoka, H.; Sato, S.; Kato, T.; Tabata, S.; Noda, T.; Ohsumi, Y. Processing of ATG8s, ubiquitin-like proteins, and their deconjugation by ATG4s are essential for plant autophagy. Plant Cell 2004, 16, 2967-2983. [CrossRef] [PubMed]

25. Suzuki, N.N.; Yoshimoto, K.; Fujioka, Y.; Ohsumi, Y.; Inagaki, F. The crystal structure of plant ATG12 and its biological implication in autophagy. Autophagy 2005, 1, 119-126. [CrossRef] [PubMed]

26. Xiong, Y.; Contento, A.L.; Bassham, D.C. AtATG18a is required for the formation of autophagosomes during nutrient stress and senescence in Arabidopsis thaliana. Plant J. 2005, 42, 535-546. [CrossRef] [PubMed]

27. Doelling, J.H.; Walker, J.M.; Friedman, E.M.; Thompson, A.R.; Vierstra, R.D. The APG8/12-activating enzyme APG7 is required for proper nutrient recycling and senescence in Arabidopsis thaliana. J. Biol. Chem. 2002, 277, 33105-33114. [CrossRef] [PubMed]

28. Phillips, A.R.; Suttangkakul, A.; Vierstra, R.D. The ATG12-conjugating enzyme ATG10 is essential for autophagic vesicle formation in Arabidopsis thaliana. Genetics 2008, 178, 1339-1353. [CrossRef] [PubMed]

29. Suttangkakul, A.; Li, F.Q.; Chung, T.; Vierstra, R.D. The ATG1/ATG13 protein kinase complex Is both a regulator and a target of autophagic recycling in Arabidopsis. Plant Cell 2011, 23, 3761-3779. [CrossRef] [PubMed]

30. Chung, T.; Phillips, A.R.; Vierstra, R.D. ATG8 lipidation and ATG8-mediated autophagy in Arabidopsis require ATG12 expressed from the differentially controlled ATG12A and ATG12B loci. Plant J. 2010, 62, 483-493. [CrossRef] [PubMed] 
31. Thompson, A.R.; Doelling, J.H.; Suttangkakul, A.; Vierstra, R.D. Autophagic nutrient recycling in Arabidopsis directed by the ATG8 and ATG12 conjugation pathways. Plant Physiol. 2005, 138, 2097-2110. [CrossRef] [PubMed]

32. Li, F.; Chung, T.; Vierstra, R.D. AUTOPHAGY-RELATED11 plays a critical role in general autophagy- and senescence-induced mitophagy in Arabidopsis. Plant Cell 2014, 26, 788-807. [CrossRef] [PubMed]

33. Mae, T.; Kai, N.; Makino, A.; Ohira, K. Relation between ribulose bisphosphate carboxylase content and chloroplast number in naturally senescing primary leaves of wheat. Plant Cell Physiol. 1984, 25, 333-336. [CrossRef]

34. Ono, K.; Hashimoto, H.; Katoh, S. Changes in the number and size of chloroplasts during senescence of primary leaves of wheat grown under different conditions. Plant Cell Physiol. 1995, 36, 9-17. [CrossRef]

35. Martinoia, E.; Heck, U.; Dalling, M.J.; Matile, P. Changes in chloroplast number and chloroplast constituents in senescing barley leaves. Biochem. Physiol. Pflanz. 1983, 178, 147-155. [CrossRef]

36. Chiba, A.; Ishida, H.; Nishizawa, N.K.; Makino, A.; Mae, T. Exclusion of ribulose-1,5-bisphosphate carboxylase/oxygenase from chloroplasts by specific bodies in naturally senescing leaves of wheat. Plant Cell Physiol. 2003, 44, 914-921. [CrossRef] [PubMed]

37. Ishida, H.; Yoshimoto, K.; Izumi, M.; Reisen, D.; Yano, Y.; Makino, A.; Ohsumi, Y.; Hanson, M.R.; Mae, T. Mobilization of rubisco and stroma-localized fluorescent proteins of chloroplasts to the vacuole by an ATG gene-dependent autophagic process. Plant Physiol. 2008, 148, 142-155. [CrossRef] [PubMed]

38. Izumi, M.; Hidema, J.; Wada, S.; Kondo, E.; Kurusu, T.; Kuchitsu, K.; Makino, A.; Ishida, H. Establishment of monitoring methods for autophagy in rice reveals autophagic recycling of chloroplasts and root plastids during energy limitation. Plant Physiol. 2015, 167, 1307-1320. [CrossRef] [PubMed]

39. Gao, C.J.; Zhuang, X.H.; Shen, J.B.; Jiang, L.W. Plant ESCRT complexes: Moving beyond endosomal sorting. Trends Plant Sci. 2017, 22, 986-998. [CrossRef] [PubMed]

40. Spitzer, C.; Li, F.Q.; Buono, R.; Roschzttardtz, H.; Chung, T.J.; Zhang, M.; Osteryoung, K.W.; Vierstra, R.D.; Otegui, M.S. The endosomal protein CHARGED MULTIVESICULAR BODY PROTEIN1 regulates the autophagic turnover of plastids in Arabidopsis. Plant Cell 2015, 27, 391-402. [CrossRef] [PubMed]

41. Izumi, M.; Wada, S.; Makino, A.; Ishida, H. The autophagic degradation of chloroplasts via rubisco-containing bodies is specifically linked to leaf carbon status but not nitrogen status in Arabidopsis. Plant Physiol. 2010, 154, 1196-1209. [CrossRef] [PubMed]

42. Izumi, M.; Hidema, J.; Makino, A.; Ishida, H. Autophagy contributes to nighttime energy availability for growth in Arabidopsis. Plant Physiol. 2013, 161, 1682-1693. [CrossRef] [PubMed]

43. Barros, J.A.S.; Cavalcanti, J.H.F.; Medeiros, D.B.; Nunes-Nesi, A.; Avin-Wittenberg, T.; Fernie, A.R.; Araujo, W.L. Autophagy deficiency compromises alternative pathways of respiration following energy deprivation in Arabidopsis thaliana. Plant Physiol. 2017, 175, 62-76. [CrossRef] [PubMed]

44. Hirota, T.; Izumi, M.; Wada, S.; Makino, A.; Ishida, H. Vacuolar protein degradation via autophagy provides substrates to amino acid catabolic pathways as an adaptive response to sugar starvation in Arabidopsis thaliana. Plant Cell Physiol. 2018. [CrossRef] [PubMed]

45. Hildebrandt, T.M.; Nesi, A.N.; Araujo, W.L.; Braun, H.P. Amino acid catabolism in plants. Mol. Plant 2015, 8 , 1563-1579. [CrossRef] [PubMed]

46. Araújo, W.L.; Ishizaki, K.; Nunes-Nesi, A.; Larson, T.R.; Tohge, T.; Krahnert, I.; Witt, S.; Obata, T.; Schauer, N.; Graham, I.A.; et al. Identification of the 2-hydroxyglutarate and Isovaleryl-CoA dehydrogenases as alternative electron donors linking lysine catabolism to the electron transport chain of Arabidopsis mitochondria. Plant Cell 2010, 22, 1549-1563. [CrossRef] [PubMed]

47. Ishizaki, K.; Larson, T.R.; Schauer, N.; Fernie, A.R.; Graham, I.A.; Leaver, C.J. The critical role of Arabidopsis electron-transfer flavoprotein: Ubiquinone oxidoreductase during dark-induced starvation. Plant Cell 2005, 17, 2587-2600. [CrossRef] [PubMed]

48. Ishizaki, K.; Schauer, N.; Larson, T.R.; Graham, I.A.; Fernie, A.R.; Leaver, C.J. The mitochondrial electron transfer flavoprotein complex is essential for survival of Arabidopsis in extended darkness. Plant J. 2006, 47, 751-760. [CrossRef] [PubMed]

49. Peng, C.; Uygun, S.; Shiu, S.H.; Last, R.L. The impact of the branched-chain ketoacid dehydrogenase complex on amino acid homeostasis in Arabidopsis. Plant Physiol. 2015, 169, 1807-1820. [CrossRef] [PubMed]

50. Liu, Y.; Xiong, Y.; Bassham, D.C. Autophagy is required for tolerance of drought and salt stress in plants. Autophagy 2009, 5, 954-963. [CrossRef] [PubMed] 
51. Chen, L.; Liao, B.; Qi, H.; Xie, L.J.; Huang, L.; Tan, W.J.; Zhai, N.; Yuan, L.B.; Zhou, Y.; Yu, L.J.; et al. Autophagy contributes to regulation of the hypoxia response during submergence in Arabidopsis thaliana. Autophagy 2015, 11, 2233-2246. [CrossRef] [PubMed]

52. Wada, S.; Ishida, H.; Izumi, M.; Yoshimoto, K.; Ohsumi, Y.; Mae, T.; Makino, A. Autophagy plays a role in chloroplast degradation during senescence in individually darkened leaves. Plant Physiol. 2009, 149, 885-893. [CrossRef] [PubMed]

53. Ono, Y.; Wada, S.; Izumi, M.; Makino, A.; Ishida, H. Evidence for contribution of autophagy to rubisco degradation during leaf senescence in Arabidopsis thaliana. Plant Cell Environ. 2013, 36, 1147-1159. [CrossRef] [PubMed]

54. Wada, S.; Hayashida, Y.; Izumi, M.; Kurusu, T.; Hanamata, S.; Kanno, K.; Kojima, S.; Yamaya, T.; Kuchitsu, K.; Makino, A.; et al. Autophagy supports biomass production and nitrogen use efficiency at the vegetative stage in rice. Plant Physiol. 2015, 168, 60-73. [CrossRef] [PubMed]

55. Guiboileau, A.; Yoshimoto, K.; Soulay, F.; Bataillé, M.P.; Avice, J.C.; Masclaux-Daubresse, C. Autophagy machinery controls nitrogen remobilization at the whole-plant level under both limiting and ample nitrate conditions in Arabidopsis. New Phytol. 2012, 194, 732-740. [CrossRef] [PubMed]

56. Li, F.Q.; Chung, T.; Pennington, J.G.; Federico, M.L.; Kaeppler, H.F.; Kaeppler, S.M.; Otegui, M.S.; Vierstra, R.D. Autophagic recycling plays a central role in maize nitrogen remobilization. Plant Cell 2015, 27, 1389-1408. [CrossRef] [PubMed]

57. Guiboileau, A.; Avila-Ospina, L.; Yoshimoto, K.; Soulay, F.; Azzopardi, M.; Marmagne, A.; Lothier, J.; Masclaux-Daubresse, C. Physiological and metabolic consequences of autophagy deficiency for the management of nitrogen and protein resources in Arabidopsis leaves depending on nitrate availability. New Phytol. 2013, 199, 683-694. [CrossRef] [PubMed]

58. Kurusu, T.; Koyano, T.; Hanamata, S.; Kubo, T.; Noguchi, Y.; Yagi, C.; Nagata, N.; Yamamoto, T.; Ohnishi, T.; Okazaki, Y.; et al. OsATG7 is required for autophagy-dependent lipid metabolism in rice postmeiotic anther development. Autophagy 2014, 10, 878-888. [CrossRef] [PubMed]

59. Ishida, H.; Izumi, M.; Wada, S.; Makino, A. Roles of autophagy in chloroplast recycling. Biochim. Biophys. Acta 2014, 1837, 512-521. [CrossRef] [PubMed]

60. Kim, J.; Lee, H.; Lee, H.N.; Kim, S.H.; Shin, K.D.; Chung, T. Autophagy-related proteins are required for degradation of peroxisomes in Arabidopsis hypocotyls during seedling growth. Plant Cell 2013, 25, 4956-4966. [CrossRef] [PubMed]

61. Shibata, M.; Oikawa, K.; Yoshimoto, K.; Kondo, M.; Mano, S.; Yamada, K.; Hayashi, M.; Sakamoto, W.; Ohsumi, Y.; Nishimura, M. Highly oxidized peroxisomes are selectively degraded via autophagy in Arabidopsis. Plant Cell 2013, 25, 4967-4983. [CrossRef] [PubMed]

62. Yoshimoto, K.; Shibata, M.; Kondo, M.; Oikawa, K.; Sato, M.; Toyooka, K.; Shirasu, K.; Nishimura, M.; Ohsumi, Y. Organ-specific quality control of plant peroxisomes is mediated by autophagy. J. Cell Sci. 2014, 127, 1161-1168. [CrossRef] [PubMed]

63. Goto-Yamada, S.; Mano, S.; Nakamori, C.; Kondo, M.; Yamawaki, R.; Kato, A.; Nishimura, M. Chaperone and protease functions of LON protease 2 modulate the peroxisomal transition and degradation with autophagy. Plant Cell Physiol. 2014, 55, 482-496. [CrossRef] [PubMed]

64. Farmer, L.M.; Rinaldi, M.A.; Young, P.G.; Danan, C.H.; Burkhart, S.E.; Bartel, B. Disrupting autophagy restores peroxisome function to an Arabidopsis lon 2 mutant and reveals a role for the LON2 protease in peroxisomal matrix protein degradation. Plant Cell 2013, 25, 4085-4100. [CrossRef] [PubMed]

65. Liu, Y.; Burgos, J.S.; Deng, Y.; Srivastava, R.; Howell, S.H.; Bassham, D.C. Degradation of the endoplasmic reticulum by autophagy during endoplasmic reticulum stress in Arabidopsis. Plant Cell 2012, 24, 4635-4651. [CrossRef] [PubMed]

66. Yang, X.C.; Srivastava, R.; Howell, S.H.; Bassham, D.C. Activation of autophagy by unfolded proteins during endoplasmic reticulum stress. Plant J. 2016, 85, 83-95. [CrossRef] [PubMed]

67. Izumi, M.; Ishida, H.; Nakamura, S.; Hidema, J. Entire photodamaged chloroplasts are transported to the central vacuole by Autophagy. Plant Cell 2017, 29, 377-394. [CrossRef] [PubMed]

68. Izumi, M.; Nakamura, S. Vacuolar digestion of entire damaged chloroplasts in Arabidopsis thaliana is accomplished by chlorophagy. Autophagy 2017, 13, 1239-1240. [CrossRef] [PubMed]

69. Izumi, M.; Nakamura, S. Partial or entire: Distinct responses of two types of chloroplast autophagy. Plant Signal. Behav. 2017, 12, e1393137. [CrossRef] [PubMed] 
70. Ichimura, Y.; Kirisako, T.; Takao, T.; Satomi, Y.; Shimonishi, Y.; Ishihara, N.; Mizushima, N.; Tanida, I.; Kominami, E.; Ohsumi, M.; et al. A ubiquitin-like system mediates protein lipidation. Nature 2000, 408, 488-492. [CrossRef] [PubMed]

71. Noda, N.N.; Ohsumi, Y.; Inagaki, F. Atg8-family interacting motif crucial for selective autophagy. FEBS Lett. 2010, 584, 1379-1385. [CrossRef] [PubMed]

72. Kanki, T.; Wang, K.; Cao, Y.; Baba, M.; Klionsky, D.J. Atg32 is a mitochondrial protein that confers selectivity during mitophagy. Dev. Cell 2009, 17, 98-109. [CrossRef] [PubMed]

73. Okamoto, K.; Kondo-Okamoto, N.; Ohsumi, Y. Mitochondria-anchored receptor Atg32 mediates degradation of mitochondria via selective autophagy. Dev. Cell 2009, 17, 87-97. [CrossRef] [PubMed]

74. Mochida, K.; Oikawa, Y.; Kimura, Y.; Kirisako, H.; Hirano, H.; Ohsumi, Y.; Nakatogawa, H. Receptor-mediated selective autophagy degrades the endoplasmic reticulum and the nucleus. Nature 2015, 522, 359-362. [CrossRef] [PubMed]

75. Honig, A.; Avin-Wittenberg, T.; Ufaz, S.; Galili, G. A new type of compartment, defined by plant-specific atg8-interacting proteins, is induced upon exposure of Arabidopsis plants to carbon starvation. Plant Cell 2012, 24, 288-303. [CrossRef] [PubMed]

76. Michaeli, S.; Honig, A.; Levanony, H.; Peled-Zehavi, H.; Galili, G. Arabidopsis ATG8-INTERACTING PROTEIN1 is involved in autophagy-dependent vesicular trafficking of plastid proteins to the vacuole. Plant Cell 2014, 26, 4084-4101. [CrossRef] [PubMed]

77. Luo, L.M.; Zhang, P.P.; Zhu, R.H.; Fu, J.; Su, J.; Zheng, J.; Wang, Z.Y.; Wang, D.; Gong, Q.Q. Autophagy is rapidly induced by salt stress and is required for salt tolerance in Arabidopsis. Front. Plant Sci. 2017, 8, 1459. [CrossRef] [PubMed]

78. Otegui, M.S.; Noh, Y.S.; Martinez, D.E.; Vila Petroff, M.G.; Andrew Staehelin, L.; Amasino, R.M.; Guiamet, J.J. Senescence-associated vacuoles with intense proteolytic activity develop in leaves of Arabidopsis and soybean. Plant J. 2005, 41, 831-844. [CrossRef] [PubMed]

79. Martinez, D.E.; Costa, M.L.; Gomez, F.M.; Otegui, M.S.; Guiamet, J.J. 'Senescence-associated vacuoles' are involved in the degradation of chloroplast proteins in tobacco leaves. Plant J. 2008, 56, 196-206. [CrossRef] [PubMed]

80. Carrion, C.A.; Costa, M.L.; Martinez, D.E.; Mohr, C.; Humbeck, K.; Guiamet, J.J. In vivo inhibition of cysteine proteases provides evidence for the involvement of 'senescence-associated vacuoles' in chloroplast protein degradation during dark-induced senescence of tobacco leaves. J. Exp. Bot. 2013, 64, 4967-4980. [CrossRef] [PubMed]

81. Wang, S.H.; Blumwald, E. Stress-induced chloroplast degradation in Arabidopsis is regulated via a process independent of autophagy and senescence-associated vacuoles. Plant Cell 2014, 26, 4875-4888. [CrossRef] [PubMed]

82. Sade, N.; Umnajkitikorn, K.; Rubio Wilhelmi, M.D.M.; Wright, M.; Wang, S.; Blumwald, E. Delaying chloroplast turnover increases water-deficit stress tolerance through the enhancement of nitrogen assimilation in rice. J. Exp. Bot. 2017, 69, 867-878. [CrossRef] [PubMed]

83. Komander, D.; Rape, M. The ubiquitin code. Annu. Rev. Biochem. 2012, 81, 203-229. [CrossRef] [PubMed]

84. Vierstra, R.D. The expanding universe of ubiquitin and ubiquitin-like modifiers. Plant Physiol. 2012, 160, 2-14. [CrossRef] [PubMed]

85. Shu, K.; Yang, W.Y. E3 ubiquitin ligases: Ubiquitous actors in plant development and abiotic stress responses. Plant Cell Physiol. 2017, 58, 1461-1476. [CrossRef] [PubMed]

86. Hua, Z.H.; Vierstra, R.D. The cullin-ring ubiquitin-protein ligases. Annu. Rev. Plant Biol. 2011, 62, $299-334$. [CrossRef] [PubMed]

87. Kraft, E.; Stone, S.L.; Ma, L.G.; Su, N.; Gao, Y.; Lau, O.S.; Deng, X.W.; Callis, J. Genome analysis and functional characterization of the E2 and RING-type E3 ligase ubiquitination enzymes of Arabidopsis. Plant Physiol. 2005, 139, 1597-1611. [CrossRef] [PubMed]

88. Stone, S.L.; Hauksdottir, H.; Troy, A.; Herschleb, J.; Kraft, E.; Callis, J. Functional analysis of the RING-type ubiquitin ligase family of Arabidopsis. Plant Physiol. 2005, 137, 13-30. [CrossRef] [PubMed]

89. Ling, Q.H.; Huang, W.H.; Baldwin, A.; Jarvis, P. Chloroplast biogenesis is regulated by direct action of the ubiquitin-proteasome system. Science 2012, 338, 655-659. [CrossRef] [PubMed]

90. Jarvis, P.; López-Juez, E. Biogenesis and homeostasis of chloroplasts and other plastids. Nat. Rev. Mol. Cell Biol. 2013, 14, 787-802. [CrossRef] [PubMed] 
91. Ling, Q.H.; Jarvis, P. Regulation of chloroplast protein import by the ubiquitin E3 Ligase SP1 is important for stress tolerance in plants. Curr. Biol. 2015, 25, 2527-2534. [CrossRef] [PubMed]

92. Woodson, J.D.; Joens, M.S.; Sinson, A.B.; Gilkerson, J.; Salom, P.A.; Weigel, D.; Fitzpatrick, J.A.; Chory, J. Ubiquitin facilitates a quality-control pathway that removes damaged chloroplasts. Science 2015, 350, 450-454. [CrossRef] [PubMed]

93. Kraft, C.; Peter, M.; Hofmann, K. Selective autophagy: Ubiquitin-mediated recognition and beyond. Nat. Cell Biol. 2010, 12, 836-841. [CrossRef] [PubMed]

94. Matsuda, N.; Sato, S.; Shiba, K.; Okatsu, K.; Saisho, K.; Gautier, C.A.; Sou, Y.S.; Saiki, S.; Kawajiri, S.; Sato, F.; et al. PINK1 stabilized by mitochondrial depolarization recruits Parkin to damaged mitochondria and activates latent Parkin for mitophagy. J. Cell Biol. 2010, 189, 211-221. [CrossRef] [PubMed]

95. Narendra, D.; Tanaka, A.; Suen, D.F.; Youle, R.J. Parkin is recruited selectively to impaired mitochondria and promotes their autophagy. J Cell Biol. 2008, 183, 795-803. [CrossRef] [PubMed]

96. Narendra, D.P.; Jin, S.M.; Tanaka, A.; Suen, D.F.; Gautier, C.A.; Shen, J.; Cookson, M.R.; Youle, R.J. PINK1 is selectively stabilized on impaired mitochondria to activate Parkin. PLoS Biol. 2010, 8, e1000298. [CrossRef] [PubMed]

97. Vives-Bauza, C.; Zhou, C.; Huang, Y.; Cui, M.; de Vries, R.L.; Kim, J.; May, J.; Tocilescu, M.A.; Liu, W.; Ko, H.S.; et al. PINK1-dependent recruitment of Parkin to mitochondria in mitophagy. Proc. Natl. Acad. Sci. USA 2010, 107, 378-383. [CrossRef] [PubMed]

98. Have, M.; Balliau, T.; Cottyn-Boitte, B.; Derond, E.; Cueff, G.; Soulay, F.; Lornac, A.; Reichman, P.; Dissmeyer, N.; Avice, J.C.; et al. Increase of proteasome and papain-like cysteine protease activities in autophagy mutants: Backup compensatory effect or pro cell-death effect? J. Exp. Bot. 2017. [CrossRef]

99. Yoshimoto, K.; Jikumaru, Y.; Kamiya, Y.; Kusano, M.; Consonni, C.; Panstruga, R.; Ohsumi, Y.; Shirasu, K. Autophagy negatively regulates cell death by controlling NPR1-dependent salicylic acid signaling during senescence and the innate immune response in Arabidopsis. Plant Cell 2009, 21, 2914-2927. [CrossRef] [PubMed]

100. Wang, P.; Sun, X.; Jia, X.; Ma, F. Apple autophagy-related protein MdATG3s afford tolerance to multiple abiotic stresses. Plant Sci. 2017, 256, 53-64. [CrossRef] [PubMed]

101. Xia, T.M.; Xiao, D.; Liu, D.; Chai, W.T.; Gong, Q.Q.; Wang, N.N. Heterologous expression of ATG8c from soybean confers tolerance to nitrogen deficiency and increases yield in Arabidopsis. PLoS ONE 2012, 7, e37217. [CrossRef] [PubMed] 